\title{
Sabella spallanzanii and Seafloor Biodiversity Enhancement in a Marine Soft-Sediment System
}

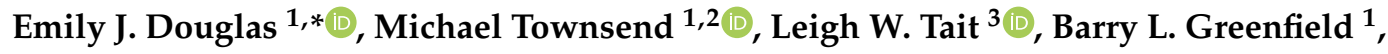 \\ Graeme J. Inglis ${ }^{3}$ and Andrew M. Lohrer ${ }^{1}$ \\ 1 National Institute of Water and Atmospheric Research, P.O. Box 11115, Hamilton 3251, New Zealand; \\ Michael.Townsend@waikatoregion.govt.nz (M.T.); barry.greenfield@niwa.co.nz (B.L.G.); \\ drew.lohrer@niwa.co.nz (A.M.L.) \\ 2 Waikato Regional Council, Private Bag 3038, Hamilton 3240, New Zealand \\ 3 National Institute of Water and Atmospheric Research, P.O. Box 8602, Christchurch 8011, New Zealand; \\ leigh.tait@niwa.co.nz (L.W.T.); Graeme.Inglis@niwa.co.nz (G.J.I.) \\ * Correspondence: emily.douglas@niwa.co.nz
}

Received: 19 April 2020; Accepted: 3 June 2020; Published: 8 June 2020

check for updates

\begin{abstract}
Predicting and managing the potential economic, social, and ecological impacts of bioinvasions is a key goal of non-indigenous species (NIS) research worldwide. The marine fan worm, Sabella spallanzanii, is an ecosystem engineering NIS that forms dense filter-feeding canopies on hard substrata and large clumps of individuals in soft sediment habitats. In this study, we investigated the epifaunal assemblages associated with Sabella clumps of increasing size and complexity from soft-sediment benthic ecosystems in Auckland Harbour, New Zealand. The diversity and abundance of epifaunal taxa increased with clump size. Species accumulation curves suggest that with further increases in Sabella clump size, diversity will continue to increase. There were no differential effects on taxa related to feeding mode or motility despite the potential for Sabella to reduce food to suspension feeders (through competition) and increase food supply to deposit feeders (through biodeposition). Our results provide an example of local biodiversity enhancement by an NIS, though some of the species benefitting from Sabella were themselves non-indigenous or of uncertain origin (cryptogenic/indeterminate). Longer term studies of the impacts of Sabella on native biodiversity and ecosystem functioning, including on food webs, are important next steps.
\end{abstract}

Keywords: ecosystem engineer; biogenic structure; biodiversity; marine soft-sediment; epifauna; non-indigenous species; species accumulation curve; Sabella spallanzanii; Atrina zelandica

\section{Introduction}

The establishment and spread of non-indigenous species (NIS) have had profound impacts on ecosystems worldwide, including effects on local habitat, biodiversity, and ecology. Biosecurity measures to limit species translocations have been adopted by global industries and governments, and plans for responding to newly detected NIS are in place in many countries [1-3]. These practices are laudable and should be expanded, given the potential for NIS to cause ecological and economic harm. However, some NIS are more harmful than others, and species that are harmful in one place may be relatively benign in another [4]. It is important to quantify impacts and evaluate them in context to improve decision making so that public expenditure on control and management of NIS can be effectively prioritized [5,6]. Information on the effects of NIS on species assemblages and ecosystem functions is crucial for understanding their success as invaders and their potential for ecosystem impacts. With serial invaders (i.e., NIS that invade several disjunct areas outside their native range in succession), past impacts are often used as means of predicting future effects in a new locale, 
but because the effects of NIS are mediated by local environmental and ecological conditions, it is important to understand which types of impacts are consistent from place to place.

Sabella spallanzanii (Gmelin, 1971) (hereafter Sabella), otherwise known as the Mediterranean fanworm, is a tube-building polychaete from the family Sabellidae. It is native to the Mediterranean and Atlantic coast of Europe and has invaded harbours throughout Australia and, more recently, New Zealand [7-9]. In New Zealand, Sabella occurs in high densities under docks and on artificial structures, including marine aquaculture facilities [10]. It is now also commonly found in natural rocky and soft-sediment benthic habitats. In soft sediment habitats, Sabella tends to settle initially on shell material, pieces of gravel, or other hard debris before becoming well anchored in the sediment and able to withstand strong currents and bed shear stresses. Sabella tubes consist of hardened secreted mucus up to $40 \mathrm{~cm}$ in length, often forming clusters or clumps of multiple individuals, especially when on natural substrates.

Sabella is a marine benthic ecosystem engineer that provides biogenic habitat structure, sometimes in areas where there would otherwise not be canopy cover, attachment surfaces, or vertical seabed relief. In addition to enhancing structural complexity, it may also provide a type of habitat different to that created by native species. This in turn may increase biodiversity and the abundance of some local species by providing a novel habitat [11]. Furthermore, some NIS persist and thrive in highly impacted and degraded environments where native habitat forming species have been lost or are unable to survive. NIS can have facilitative impacts on recipient communities by (1) providing a limiting resource, (2) increasing habitat complexity, (3) fulfilling the functional role of lost native species, or (4) providing significant escape from enemies or competitors [12]. At our study site, the Waitemata Harbour in Northern New Zealand, Sabella exist where dense beds of native habitat-forming shellfish Atrina zelandica were once common $[13,14]$. Only isolated A. zelandica individuals have been observed near the study site during the last $10+$ years, part of a pattern of loss that has also been reported in other parts of northern New Zealand [15].

Enhancement of recipient community richness and abundance (particularly marine epifauna) has been demonstrated for a number of habitat forming NIS (e.g., [12,16-19]), but facilitation effects of Sabella on epifauna have only been demonstrated in one place [20], and its influence is likely to be highly context-dependent and location-specific. Holloway and Keough [21] found that epifaunal species assemblages beneath high density Sabella canopies on hard substrata differed significantly (e.g., more sponges and three times more Anomia sp. bivalves, but fewer bryozoans) compared with areas cleared of Sabella. However, this effect may not hold true for soft sediment ecosystems. As many NIS can vary widely in terms of the latitudes and ecosystems (and local communities) they colonise, impacts in one area may differ greatly from those in another [22].

NIS suspension feeders may facilitate faunal communities in similar ways to invasive plants, through provision of food and habitat [18]. Assemblages of epifaunal organisms form as a function of recruitment processes as well as post-recruitment selection pressures, such as competition for food and space. Sabella canopies have the potential to alter both of these by feeding on planktonic larvae, reducing food availability or quality for other suspension feeders, or increasing/decreasing appropriate settlement surfaces for other species [23,24]. Faecal and pseudofaecal material deposited to the seabed by Sabella can provide food for deposit feeders and alter benthic biogeochemistry, and the worms can also produce chemical cues that may enhance or prevent colonisation and settlement of other species [25]. The productivity of benthic communities can be influenced by organisms like Sabella that contribute to organic matter deposition and mineralisation in the sediments [26,27].

Alteration of near-bed hydrodynamics by Sabella canopies can affect recruitment and settlement of other organisms. For example, Sabella has been shown to reduce the recruitment of sessile taxa to hard substrates [20,21]. In soft sediment environments, Sabella may increase the availability of settlement surfaces (i.e., provision of secondary space $[20,28]$ ) for sedentary epifaunal taxa that require 'hard' substrate. For mobile epifauna, Sabella clumps may provide area for grazing, foraging, and shelter from predators. By these mechanisms, Sabella has the potential to affect the trophic composition of 
native species assemblages in both epifaunal and infaunal benthic communities. These effects are likely to scale with the size and surface area of Sabella clumps, consistent with classical species-area relationship theory, which, in its most simple form, predicts an increasing number of species with increasing habitat size $[29,30]$.

Here, we tested the effect of Sabella clump size on the epifaunal community composition, specifically whether (1) Sabella clump size affected the diversity and abundance of epifaunal taxa, and (2) increasing Sabella clump size disproportionately affected the diversity of taxa with different feeding modes or motilities. We expected that clumps of Sabella would provide biogenic seabed structure and, therefore, provide surface area and habitat for epifauna that would not otherwise be present on uninvaded bare sediment (i.e., novel facilitation, sensu Rodriguez [12]). Furthermore, we expected that the size of the Sabella clumps would increase the abundance and diversity of the associated epifaunal community. We were interested in the effects of Sabella on native versus non-native epifaunal taxa, though the taxonomic resolution and cryptogenic/indeterminate status of some species (i.e., not clearly native or non-native [31,32]) prevented such comparisons. We hypothesised that suspension feeders may be hindered by increasing clump size owing to competition for food from filtering Sabella canopies, and that deposit feeders may increase with increasing clump size owing to higher availability of organic rich biodeposits from Sabella [33]. For both motile and sedentary species, we expected that larger clumps that provide more structural habitat complexity would host a higher number of taxa. Finally, we used species accumulation curves to gauge how further increases in Sabella clump sizes (a proxy for further spread and expansion of this NIS) would influence epifaunal diversity and epifaunal community composition.

\section{Methods}

\subsection{Field Sampling}

Sampling was conducted in the Rangitoto Channel (174.83877, 36.81350), outside Waitemata Harbour and near Auckland City's port, marinas, and shipping lanes. Rangitoto Channel is subject to wind waves, high turbidity, and strong tidal currents. The study site was a soft-sediment seafloor habitat of 8-10 m depth, where Sabella was found to be common-to-abundant in clumps of varying density on the seabed. An approximately equal number of low-, medium-, and high-density Sabella clumps was collected by divers from an area of approximately $400 \mathrm{~m}^{2}$ ('low' = 1-5 Sabella, 'medium' = 5-10 Sabella, 'high' $>10$ Sabella; $n=15$ clumps total). Entire clumps of Sabella and associated epifauna were carefully removed from the seabed and placed in mesh bags ( $20 \mu \mathrm{m}$ mesh). Everything inside each mesh bag was later preserved in $70 \%$ isopropyl alcohol.

\subsection{Laboratory Analysis}

In the laboratory, the preserved samples were stained with Rose Bengal prior to being sorted. Clumps were washed and sieved over $500 \mu \mathrm{m}$ mesh screens, collecting all faunal living on and within the Sabella clumps including within the accumulated sediment contained by the clumps. All encrusting life was removed from Sabella tubes, and tubes were separated and individually weighed (blotted wet weight) and measured (length, largest diameter). These measurements were used to calculate the volume and surface area of each tube and then summed to get the total surface area and volume metrics for each clump. Fan coverage was not accounted for in clump size metrics. All individuals $>500 \mu \mathrm{m}$ were counted and identified to the lowest possible taxonomic level by expert parataxonomists at the National Institute of Water \& Atmospheric Research Ltd. in Hamilton, with specimens sent to specialist polychaete, crustacean, and bivalve taxonomists for identification when required. We estimated the volumes of any encrusting species covering a surface area of $>2 \mathrm{~cm}^{2}$. Colonial organisms were given counts of one unless multiple separate colonies present on the same clump were able to be distinguished. 


\subsection{Traits Analysis}

Epifaunal taxa were grouped by feeding mode (suspension feeder, deposit feeder, or predator/ scavenger) and motility (motile, sedentary) using a previously developed functional traits database $[34,35]$. Taxa were counted in a feeding mode group if they were obligate or facultative (i.e., some taxa were both suspension and deposit feeders and thus were included in both groups). Feeding categories in this traits database were "fuzzy coded"; that is, taxa that can switch between suspension feeding and deposit feeding modes can be categorised as both [36]. Example species include the suspension/deposit feeding polychaete, Boccardia syrtis (Family Spionidae), and the bristled black-finger crab, Pilumnus novaezelandiae (Family Pilumnidae), which is both a deposit feeder and a scavenger. Motile taxa included those that were classed as having limited motility, were freely motile, or were semi-pelagic.

\subsection{Data Analysis}

Exploratory analyses included distance-based linear models (DistLM, Primer 7) [37] to investigate drivers of patterns in epifaunal diversity measures. These showed that Sabella clump size (surface area, volume) accounted for nearly all the explained variability in models $(>73 \%)$ and were thus core to subsequent analyses presented. Primer 7 [37] was used to calculate the cumulative number of distinct taxa observed (on average) as the number of samples, number of tubes per clump, and surface area of clumps increased. Species accumulation curves were generated using Sigmaplot 14.

\section{Results}

The epifauna associated with Sabella clumps in the study included 132 taxa representing 15 phyla (Table S1). Most taxa (85) were classed as motile and 45 were sedentary. Taxa were grouped by feeding mode with 51 taxa classed as suspension feeders, 32 as deposit feeders, and 24 as predator/scavengers (some species had more than one feeding mode and included in more than one group).

Sabella clump surface area (SA) increased linearly with the number of tubes per clump (Figure 1a). Sabella clump volume also increased with the number of tubes per clump, but followed a logarithmic curve (Figure 1b). On average, encrusting epifauna made up $31 \%$ of the total clump volume (Sabella volume + encrusting volume). Hydroids and bryozoans accounted for most of the volume of the encrusting life on Sabella clumps, together making up on average $17 \% \pm 2 \%$ of the total clump volume. The volume of encrusting epifauna increased with increasing Sabella volume; fitted curves suggested that, as clump size increases, the relative volume of encrusting epifauna increases (Figure 1b).

Although many organisms were unable to be identified down to species or genus level, the total abundance of epifauna and number of epifaunal taxa per clump increased with increasing Sabella clump size (Figure 2). SA was strongly correlated with both epifaunal abundance (Pearson's $\mathrm{R}^{2}=0.89$ ) and taxonomic richness (Pearson's $R^{2}=0.76$ ) (Figure 2). A total of 132 epifaunal taxa were identified associated with Sabella in this study, with the largest clump of 26 Sabella hosting 70 distinct taxa. A small clump comprised of just two Sabella hosted 20 taxa. The relationship between epifaunal abundance and taxa per clump was positive, following a logarithmic function $\left(R^{2}=0.76\right.$; Figure 3). Syllidae worms and Ischyroceridae amphipods were the most numerically dominant epifaunal taxa, occurring in densities of up to $\sim 800$ per Sabella clump. 
Several non-indigenous and cryptogenic species were identified among the organisms found associated with Sabella clumps. In addition to small Sabella recruits that were observed on 10 of the 15 clumps (abundance between 1 and 31 recruits per sample), colonies of the lobate encrusting bryozoan, Watersipora subtorquata, an NIS in New Zealand, were present on 13 of the 15 clumps sampled. The non-indigenous semelid bivalve, Theora lubrica, was present in low abundance (one to six individuals) in 10 of the 15 samples. The non-indigenous limid bivalve, Limaria orientalis, was associated with 8 of the 15 clumps (more than five individuals per clump in five of the clumps). One non-indigenous solitary ascidian, Styela clava, was observed. Several other species with cosmopolitan distributions and insufficient taxonomic or biogeographical information to determine whether New Zealand is within their indigenous range [32] were also observed, including Caprella sp., Chaetopterus sp., Capitella sp., Heteromastus filiformis, Botrylloides sp., other colonial ascidians, and several encrusting and erect bryozoans.
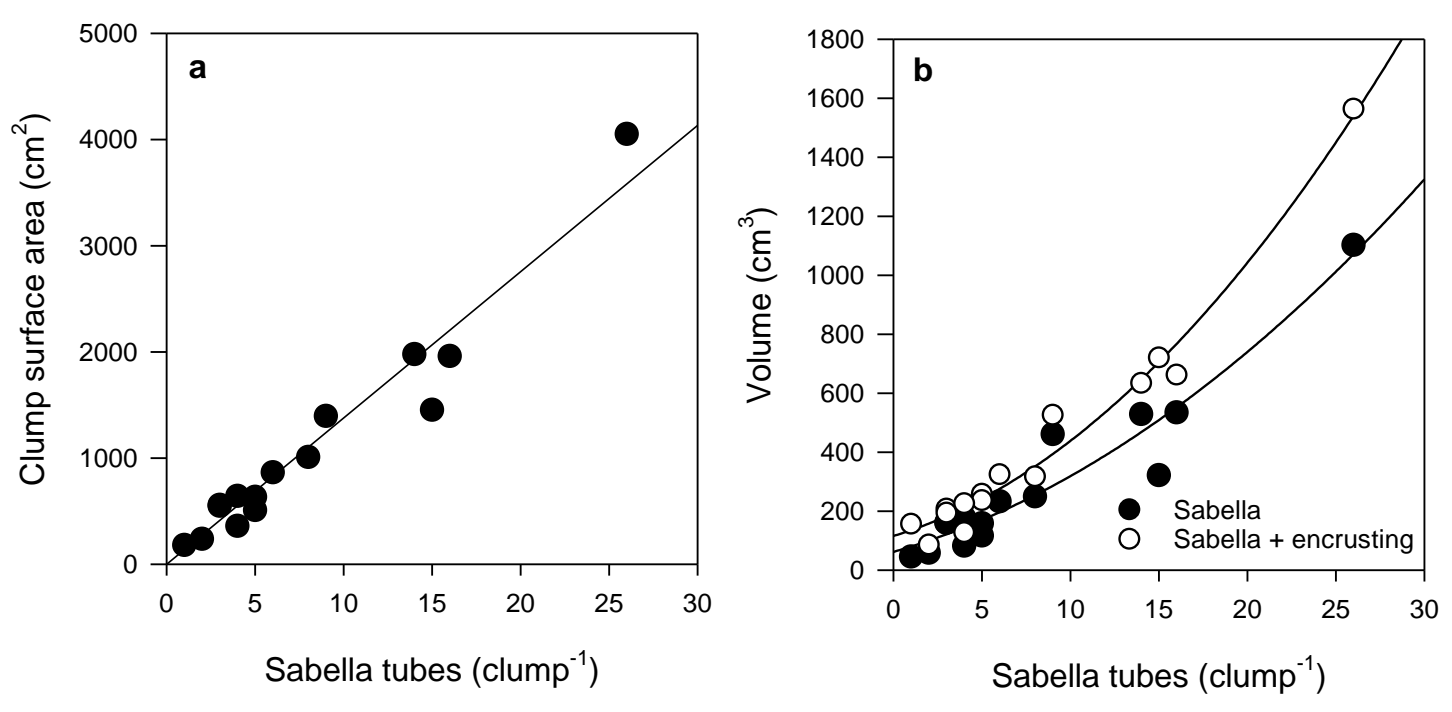

Figure 1. Relationship between (a) number of Sabella tubes and clump surface area (SA) (linear regression $\mathrm{R}^{2}=0.94, n=15$ ), and (b) volume of Sabella and the total volume of Sabella (polynomial regression $\mathrm{R}^{2}=0.92, n=15$ ) and encrusting epifauna (polynomial regression $\mathrm{R}^{2}=0.98, n=15$ ) in each clump. See Table $\mathrm{S} 2$ for further curve fit detail.
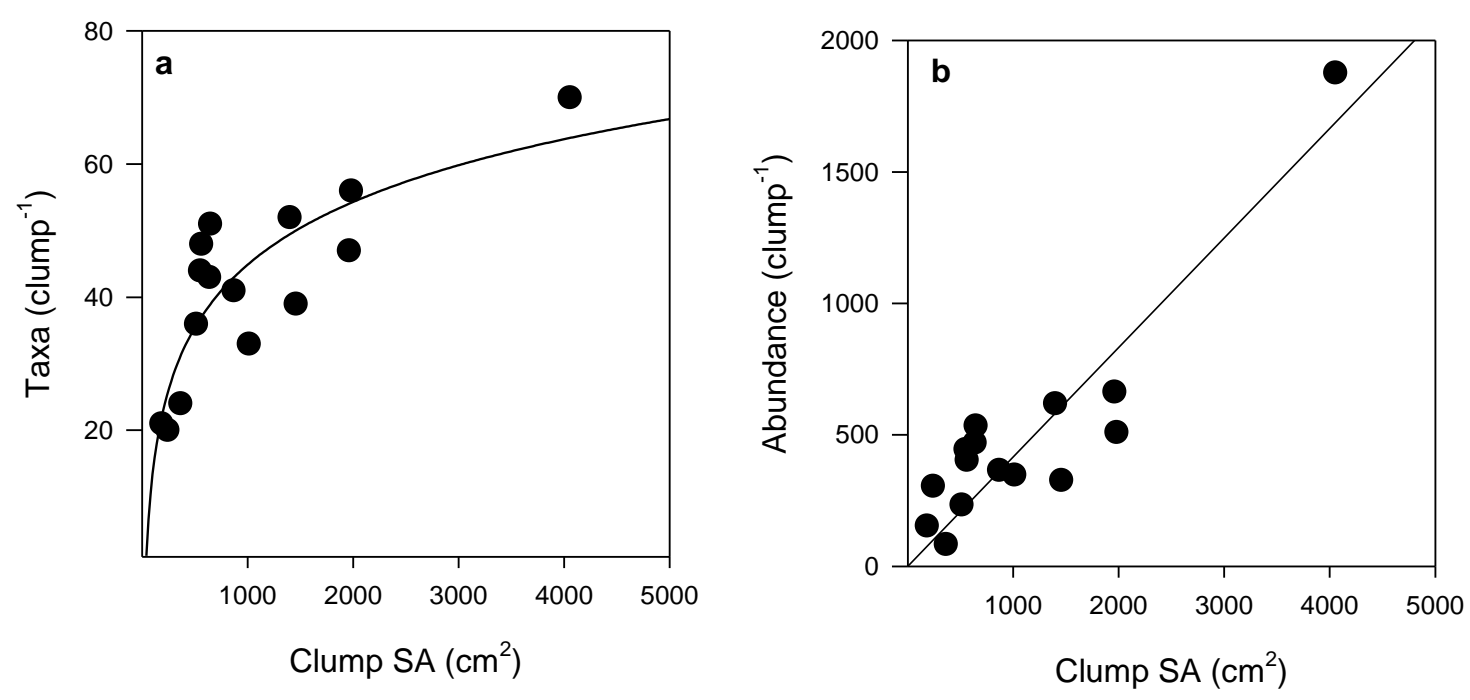

Figure 2. (a) Number of taxa (logarithmic curve fit, $\mathrm{R}^{2}=0.68, n=15$ ) and (b) abundance of epifaunal communities (linear regression $\mathrm{R}^{2}=0.82, n=15$ ) associated with Sabella clumps with increasing surface area (SA). See Table S2 for further curve fit detail. 
Over half of the taxa observed in the samples were obligate or facultative suspension feeders, and motile taxa were more abundant than sedentary taxa. The number of taxa for the feeding mode groups and both motile and sedentary taxa increased steeply up to a clump SA of about $500 \mathrm{~cm}^{2}$, after which further increases in number of taxa per clump for all groups occurred over larger increases in SA (Figure 4).

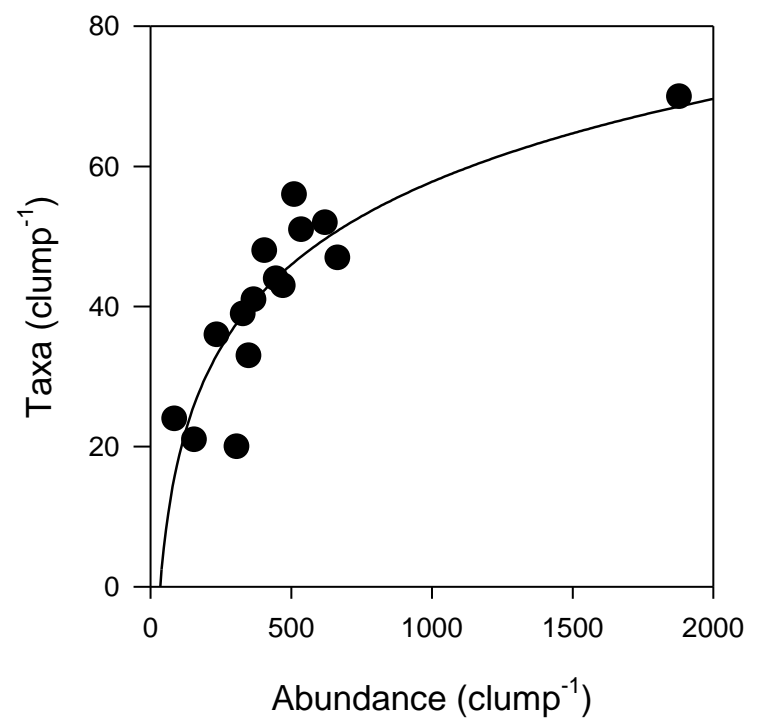

Figure 3. Epifaunal abundance and number of epifaunal taxa per Sabella clump (logarithmic curve fit, $\mathrm{R}^{2}=0.76, n=15$, see Table S2 for further detail).
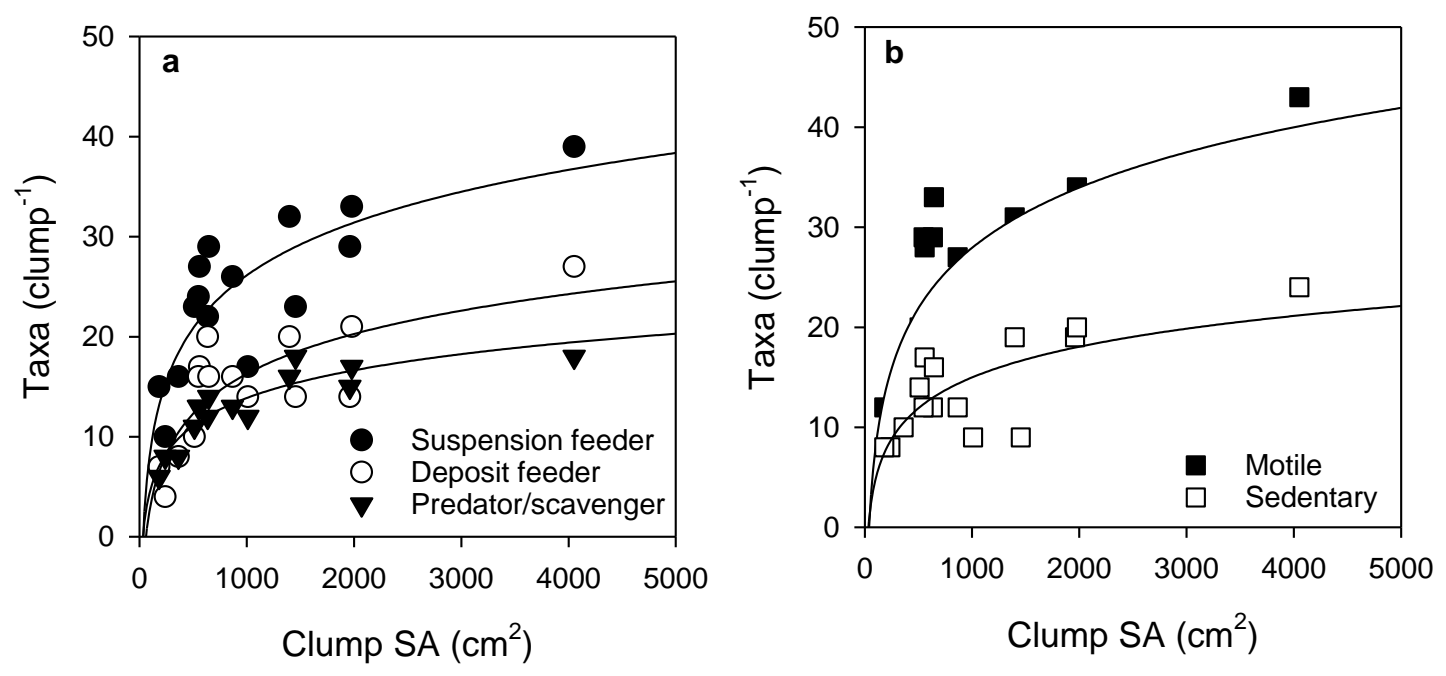

Figure 4. Relationship between Sabella clump surface area and epifauna taxa according to (a) feeding mode and (b) motility. Fitted curves all follow logarithmic equations (curve $\mathrm{R}^{2}$ values: suspension feeder (0.69), deposit feeder (0.65), predator/scavenger (0.85), motile (0.69), sedentary (0.55), see Table S2 for further detail). 
Species accumulation curves did not asymptote within our sampling range; exhibiting logarithmic fits $\left(R^{2}>0.88\right.$ in all cases; Figures 5 and 6). Curve shapes were very similar for taxa with different feeding modes. However, for species motility, curves suggest that, with further sampling effort and increases in Sabella clump size, motile species will continue to accumulate at a greater rate than sedentary species.
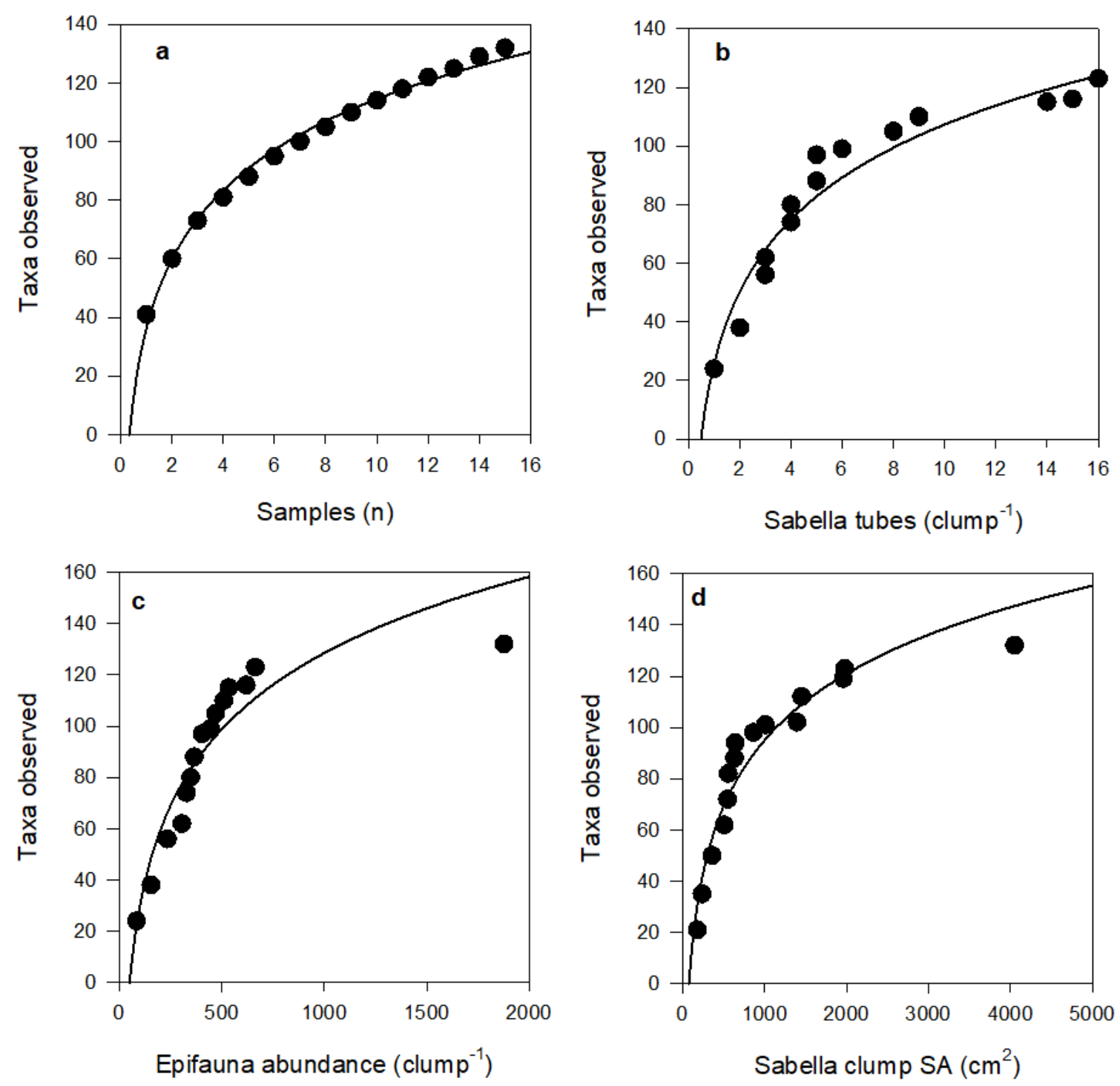

Figure 5. Species accumulation plots showing cumulative number of observed taxa with (a) number of Sabella clump samples $\left(R^{2}=0.99\right)$, (b) number of Sabella tubes per clump $\left(R^{2}=0.94\right)$, (c) epifaunal abundance per clump $\left(R^{2}=0.88\right)$, and $(d)$ Sabella clump surface area $\left(R^{2}=0.93\right)$. Fitted curves all follow logarithmic equations, see Table S2 for further detail. 

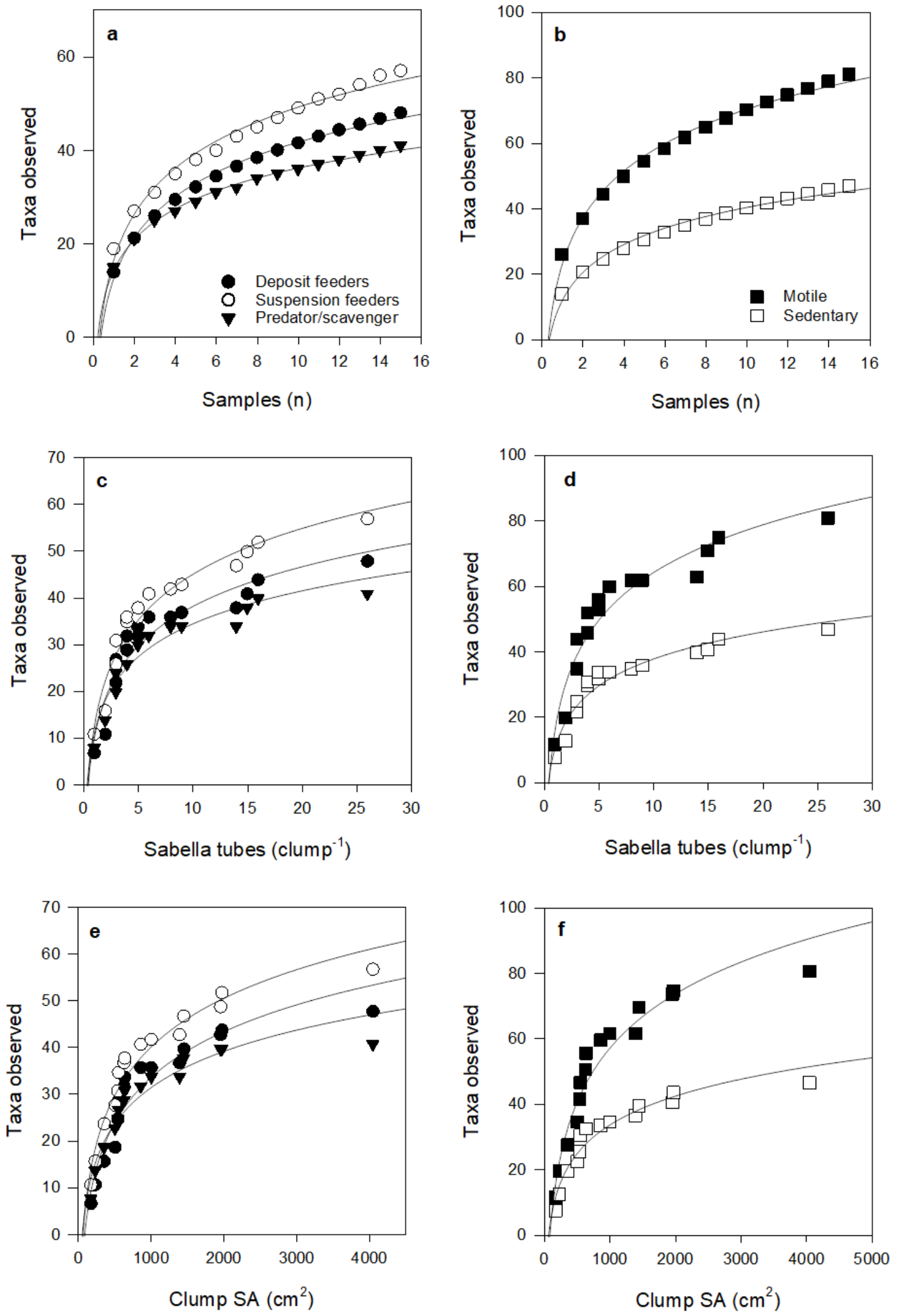

Figure 6. Species accumulation curves for taxa according to feeding mode and motility, with increasing number of Sabella clump samples $(\mathbf{a}, \mathbf{b})$, number of Sabella tubes per clump $(\mathbf{c}, \mathbf{d})$, and Sabella clump surface area $(\mathbf{e}, \mathbf{f})$. Fitted curves all follow logarithmic equations (all $\mathrm{R}^{2}>0.9$ ), see Table S2 for further detail. 


\section{Discussion}

This study gives an example of how an NIS can enhance biodiversity through provision of habitat in an area where other types of native biogenic habitat formers (e.g., pinnid bivalves and sponges) are relatively rare to absent. It supports the notion that invaders can increase biodiversity, especially in degraded areas where native habitat formers have been lost [17]. However, a higher abundance, richness, and diversity of fauna in association with habitat forming non-indigenous species does not necessarily mean native communities are benefiting from the invasion. Biodiversity effects need to be assessed at the community level (i.e., effects on taxa of varying functional types) and at different spatial and temporal scales. Moreover, the biodiversity enhanced by Sabella in this study included an unknown proportion of native, NIS, cryptogenic, and indeterminate taxa.

The type of biodiversity enhancement we observed is different than 'substitutive facilitation' [12], where a non-indigenous structure former displaces a native structure former, for example, by outcompeting it. Here, the NIS fills a somewhat novel role as a biogenic habitat former only because the native structure formers have disappeared coincident with other stressors. The role of Sabella is comparable to that of the bivalve Atrina zelandica (horse mussel, Pinnidae). Horse mussel beds were once common in soft-sediment habitats in many New Zealand harbours, including in Rangitoto Channel [14], the location of our study. Like Sabella, A. zelandica is a large filter-feeding species that protrudes above the sediment-water interface, increasing the vertical relief of the habitat and creating settlement surfaces for epifauna. A. zelandica has significantly declined in recent decades associated with elevated sedimentation and physical seabed disturbance $[14,15,38]$. Worldwide, Atrina spp. are known to host a variety of epifaunal species on their shells (including soft-corals, hydroids, sponges, ascidians, bryozoans, and mobile fauna such as crabs, nudibranchs, and holothurians; A.M.L., pers. obs., [39-41]), although quantitative assessments of epifaunal diversity on live or dead A. zelandica shells have not to our knowledge been undertaken.

Unlike Sabella, A. zelandica does not occur as clumps or clusters of multiple interconnected individuals, and A. zelandica creates a more rigid habitat in comparison with the flexible tubes of Sabella. In proximity to $A$. zelandica beds, infaunal macrobenthic communities, sediment properties, and ecosystem functions are known to differ from ambient conditions, effects that are also dependent on patch size [42-44]. In contrast, studies of invasive Sabella in Australia, and another in the Waitemata Harbour, New Zealand, indicate little effect on local infaunal assemblages (or on species richness measures), though this may be dependent on the range of Sabella densities that was investigated $[33,45,46]$.

It is generally accepted that, with increasing architectural complexity, habitats can host an increasing abundance and diversity of fauna [47-50]. As Sabella clump size increases, so does habitat complexity and, consequently, clumps can host greater abundance and diversity of epifauna. This occurs as a result of a greater range of Sabella tube sizes, and the added architectural complexity from varying forms of encrusting epifauna. In our study, encrusting organisms increased the size of Sabella clumps and, therefore, the surface area and number of micro-habitats for both sedentary and mobile epifauna. Accounting for $17 \%$ of total clump volume on average, branching hydroids and bryozoans added considerable architectural complexity to the underlying Sabella clump structure. These clumps are likely a significant novel habitat resource that would otherwise not be present at the site.

Ischyroceridae amphipods were some of the most abundant epifauna on Sabella clumps; they are motile suspension feeders that showed a distinct association with bryozoans (Catenicella sp.). This is an example of the cascading effect a foundational, ecosystem engineering NIS can have on communities and food webs. Sabella clumps of increasing size provided substrate for encrusting life (e.g., hydroids, ascidians, and bryozoans), which significantly increased the surface area of clumps and provided complex habitat space (different from the Sabella themselves) for high densities of small mobile fauna. Such high densities of mobile fauna likely contribute to local food webs by providing a food source for larger predators, in addition to detrital inputs to the seafloor and excreted nutrients to the water column. 
We tested the effect of Sabella density on epifauna with different feeding modes (suspension feeders, deposit feeders, and predator/scavengers) and motilities (motile versus sedentary), as facilitation effects of NIS have previously been shown to differ by trophic level and feeding and motility traits $[19,20]$. Differential effects on taxa with respect to feeding or motility types were not evident from our study. Thus, although many taxa were not able to be identified to species level, we do not expect there to be significant effects on wider ecosystem trophic structure. However, there could be small influences on food webs through enhanced food for higher trophic levels such as fish [51].

Similar numbers of suspension feeding, deposit feeding, and predatory/scavenging taxa colonised small Sabella clumps, and species accumulation curves were largely similar to those observed with increasing clump SA. These patterns suggest that the Sabella themselves are not disproportionately enhancing or hindering epifauna of different feeding modes. We expected that dense Sabella canopies might reduce food availability for other suspension feeders and enhance food availability for deposit feeders through bio-deposits; however, our data showed no evidence of these effects. Similarly, studies of Sabella in Port Phillip Bay in Australia were unable to detect differential effects on species with different feeding modes even with very high densities of Sabella [33]. The very high flow and relatively high seston concentrations in the bottom water at our study site (A.M.L., pers. obs.) may have limited the effects of competition for food to below detectable levels. Moreover, there is evidence that Sabella may sequester a proportion of their organic rich biodeposits, binding them with mucus to construct their tubes [52], rather than releasing all their biodeposits to the surrounding environment. The proportion of biodeposits that was released by the worms may not have settled on the worm clumps themselves owing to high current flows that sway the Sabella tubes and fans back and forth. The effects of local enrichment by Sabella would have been dampened by both biodeposit retention and the oscillating tidal currents that run through the Rangitoto Channel.

Both sedentary and motile species richness and abundance increased at similar rates with clump surface area up to about $500 \mathrm{~cm}^{2}$, but with further increases in clump size, sedentary taxa accumulated at a much slower rate than motile taxa (Figure 6e). Competition for space may play a role in the community composition and diversity of sedentary epifauna, where fewer more competitive species dominate assemblages on larger or older clumps (e.g., sponges and colonial ascidians that can overgrow other species [53]). The fitted curves also suggest that motile taxa will continue to increase at a faster rate than sedentary species for clumps larger than those included in our study (Figure $6 \mathrm{~b}, \mathrm{~d}, \mathrm{f})$. This positive effect on motile taxa may be attributed to greater provision of space for shelter and feeding as Sabella clump size increases, and that bigger taxa can be accommodated on larger, but not smaller clumps.

Facilitative effects of NIS may have more than localised effects on food webs and ecosystems, because they are likely to change wider community and trophic structure by influencing predation, competition, and herbivory [12]. Therefore, it is important to view any localised positive effects on biodiversity in a wider ecosystem context. Our traits-based analyses show that Sabella facilitate the presence of epibiota in soft-sediment environments by providing more habitat, shelter, settlement surfaces, grazing, and feeding area as clump size increases, and that these effects are neither detrimental nor beneficial for particular functional components of the epifaunal community. However, disproportionate effects on single, key native species that have the potential to alter local communities would not be detected by this study, but could change local community dynamics. Ficopomatus enigmaticus, family Serpulidae, is a tubeworm that builds calcareous tubes that form significant reefs. It is invasive on the Atlantic coast of France (and other parts of the world including New Zealand), where it is known to enhance a native crab (Cyrtograpsus angulatus) by providing a habitat allowing it to exist in very high densities that would otherwise not occur [54]. In turn, this single predatory crab species has significant negative impacts on native prey species and the structure of the local reef communities. It is possible that Sabella could have similar indirect influences on local benthic and epifaunal communities in New Zealand harbours.

Other recent work on Sabella in New Zealand suggests that its modification of benthic boundary flows and provision of habitat for epifaunal organisms may be a mechanism by which it alters 
soft-sediment biogeochemistry and solute fluxes [55]. Higher densities of Sabella in that New Zealand study resulted in higher rates of soft-sediment oxygen consumption and ammonium release, likely linked to greater respiration and excretion by the Sabella themselves, but also enhanced by the presence of higher epifaunal community densities. Sabella and associated epibiota can also influence local biogeochemistry by intercepting organic nitrogen (filter feeding) and excreting it back to the water column, thereby bypassing important benthic removal processes such as denitrification [56]. Recent work on Sabella populations in New Zealand are consistent with Australian findings, namely the limited impact of Sabella on surrounding infaunal species richness (although some assemblage composition changes occurred), but potential effects on soft-sediment biogeochemistry and solute fluxes (oxygen consumption and inorganic nitrogen regeneration/removal) ([55]; see also [46]). Negative effects of Sabella on denitrification (a microbially mediated inorganic nitrogen removal pathway) may have negative implications for coastal estuaries in New Zealand that are under increased eutrophication pressure owing to changes in human populations and land uses in coastal catchments.

Key factors that influence the impact of an ecosystem engineering species include the life span of the engineer, its population density, and its spatial distribution [57]. As Sabella spreads throughout soft-sediment ecosystems and its densities increase, trends in the diversity and abundance of epifaunal taxa will likely change. We have shown that even small clumps of Sabella provide habitat for a diverse range of epifaunal species that would otherwise not be present in a soft-sediment benthic ecosystem without biogenic structure (e.g., no bryozoans, hydroids, colonial ascidians, or sponges were found to be present in macrofaunal core samples collected at the same study site during the same summer; [55]). Sabella in this context may be considered an early-succession ecosystem engineer, as the presence of this species and the habitat it provides is relatively new. The longer-term impacts of this NIS on local and regional biodiversity could be much different than the local effects on epifauna reported here, though other studies suggest that the effects of Sabella on assemblages are greatest in the early stages of recruitment ( $<6$ months) [21]. The degree to which Sabella will have significant wider effects that need to be considered for ongoing management remains in question (e.g., [10]). Experimental studies and comprehensive monitoring of epifaunal communities over time across gradients in Sabella density are required to evaluate the wider effects of this NIS on local food webs and ecosystems.

As the size and extent of Sabella clumps continue to increase, the habitat they are providing will change, as will the species occupying it. Species accumulation curves suggest that epifaunal taxa richness will continue to increase if Sabella clumps become larger; therefore, further increases in Sabella density may further enhance local biodiversity. If Sabella densities become very high, these clump habitats may dominate or replace the existing soft sediment habitats, with the potential to either positively or negatively impact the benthic communities [12]. Although further studies are required to fully understand the long-term and wider ecological effects of Sabella on biodiversity and food webs in invaded soft sediment habitats in New Zealand harbours, this study demonstrates positive patch-scale effects on biodiversity with potential flow on effects to wider food webs.

Supplementary Materials: The following are available online at http://www.mdpi.com/1424-2818/12/6/228/s1, Table S1: Epifauna, Table S2: Curve fit statistics.

Author Contributions: Conceptualization, M.T. and A.M.L.; Methodology, M.T., A.M.L., and E.J.D.; Validation, A.M.L. and G.J.I.; Formal Analysis, E.J.D.; Investigation, B.L.G. and E.J.D.; Data Curation, B.L.G. and E.J.D.; Writing-Original Draft Preparation, E.J.D.; Writing—Review \& Editing, E.J.D., A.M.L., M.T., L.W.T., B.L.G., and G.J.I.; Visualization, E.J.D.; Supervision, A.M.L.; Project Administration, G.J.I.; Funding Acquisition, G.J.I. All authors have read and agreed to the published version of the manuscript.

Funding: This research was funded by the New Zealand Ministry of Business, Innovation and Employment (MBIE) Contract No. C01X1511; What's at stake?-Enabling decision-making through better measurement, forecasting and evaluation of the impacts of non-native organisms in NZ's changing ocean.

Acknowledgments: We would like to thank Sarah Hailes and Lisa McCartain for assistance processing samples and the divers and personnel involved with the field work aboard RV Rangitahi III. We are grateful to Judi Hewitt for providing statistical advice and feedback on the manuscript draft.

Conflicts of Interest: The authors declare no conflict of interest. 


\section{References}

1. Endresen, O.; Lee Behrens, H.; Brynestad, S.; Bjorn Andersen, A.; Skjong, R. Challenges in global ballast water management. Mar. Pollut. Bull. 2004, 48, 615-623. [CrossRef]

2. Hayes, K.R.; Inglis, G.J.; Barry, S.C. The assessment and management of marine pest risks posed by shipping: The Australian and New Zealand experience. Front. Mar. Sci. 2019, 6, 489. [CrossRef]

3. Roberts, J.; Tsamenyi, M. International legal options for the control of biofouling on international vessels. Mar. Policy 2008, 32, 559-569. [CrossRef]

4. Katsanevakis, S.; Wallentinus, I.; Zenetos, A.; Leppäkoski, E.; Çinar, M.; Bayram, O.; Grabowski, M.; Golani, D.; Cardoso, A. Impacts of invasive alien marine species on ecosystem services and biodiversity: A pan-European review. Aqua. Invasions 2014, 9, 391-423. [CrossRef]

5. Cook, D.C.; Fraser, R.W.; Waage, J.K.; Thomas, M.B. Prioritising biosecurity investment between agricultural and environmental systems. J. Verbrauch. Lebensm. 2011, 6, 3-13. [CrossRef]

6. Finnoff, D.; Shogren, J.F.; Leung, B.; Lodge, D. Take a risk: Preferring prevention over control of biological invaders. Ecol. Econ. 2007, 62, 216-222. [CrossRef]

7. Clapin, G.; Evans, D. The Status of the Introduced Marine Fanworm Sabella spallanzanii in Western Australia: A Preliminary Investigation; Technical Report; CSIRO Division of Fisheries, Centre for Research on Introduced Marine Pests: Sutherland Shire, Australia, 1995; Volume 2, pp. 1-34.

8. Currie, D.R.; McArthur, M.A.; Cohen, B.F. Reproduction and distribution of the invasive European fanworm Sabella spallanzanii (Polychaeta: Sabellidae) in Port Phillip Bay, Victoria, Australia. Mar. Biol. 2000, 136, 645-656. [CrossRef]

9. Read, G.; Inglis, G.; Stratford, P.; Ahyong, S. Arrival of the alien fanworm Sabella spallanzanii (Gmelin, 1791) (Polychaeta: Sabellidae) in two New Zealand harbours. Aqua. Invasions 2011, 6, 273-279. [CrossRef]

10. Soliman, T.; Inglis, G.J. Forecasting the economic impacts of two biofouling invaders on aquaculture production of green-lipped mussels Perna canaliculus in New Zealand. Aquac. Environ. Interact. 2018, 10, 1-12. [CrossRef]

11. Jones, C.G.; Lawton, J.H.; Shachak, M. Positive and negative effects of organisms as physical ecosystem engineers. Ecology 1997, 78, 1946-1957. [CrossRef]

12. Rodriguez, L.F. Can invasive species facilitate native species? Evidence of how, when, and why these impacts occur. Biol. Invasions 2006, 8, 927-939. [CrossRef]

13. Hayward, B.W.; Stephenson, A.B.; Morley, M.; Riley, J.L.; Grenfell, H.R. Faunal changes in Waitemata Harbour sediments, 1930s-1990s. J. R. Soc. N. Z. 1997, 27, 1-20. [CrossRef]

14. Hayward, B.; Morley, M.; Hayward, J.; Stephenson, A.; Blom, W.; Hayward, K.; Grenfell, H. Monitoring studies of the benthic ecology of Waitemata Harbour, New Zealand. Rec. Auckl. Mus. 1999, 36, 95-117.

15. Cummings, V.; Halliday, J.; Thrush, S.; Hancock, N.; Funnell, G. Mahurangi Estuary Ecological Monitoring Programme-Report on Data Collected from July 1994 to January 2005; Auckland Regional Council Technical Publication 277; Auckland Regional Council: Auckland, New Zealand, 2005; p. 102.

16. Crooks, J.A. Habitat alteration and community-level effects of an exotic mussel, Musculista senhousia. Mar. Ecol. Prog. Ser. 1998, 162, 137-152. [CrossRef]

17. Ramus, A.P.; Silliman, B.R.; Thomsen, M.S.; Long, Z.T. An invasive foundation species enhances multifunctionality in a coastal ecosystem. Proc. Natl. Acad. Sci. USA 2017, 114, 8580-8585. [CrossRef] [PubMed]

18. Thomsen, M.S.; Byers, J.E.; Schiel, D.R.; Bruno, J.F.; Olden, J.D.; Wernberg, T.; Silliman, B.R. Impacts of marine invaders on biodiversity depend on trophic position and functional similarity. Mar. Ecol. Prog. Ser. 2014, 495, 39-47. [CrossRef]

19. Sellheim, K.; Stachowicz, J.J.; Coates, R.C. Effects of a nonnative habitat-forming species on mobile and sessile epifaunal communities. Mar. Ecol. Prog. Ser. 2010, 398, 69-80. [CrossRef]

20. Holloway, M.G.; Keough, M.J. An introduced polychaete affects recruitment and larval abundance of sessile invertebrates. Ecol. Appl. 2002, 12, 1803-1823. [CrossRef]

21. Holloway, M.G.; Keough, M.J. Effects of an introduced polychaete, Sabella spallanzanii, on the development of epifaunal assemblages. Mar. Ecol. Prog. Ser. 2002, 236, 137-154. [CrossRef] 
22. Ruiz, G.M.; Fofonoff, P.; Hines, A.H.; Grosholz, E.D. Non-indigenous species as stressors in estuarine and marine communities: Assessing invasion impacts and interactions. Limnol. Oceanogr. 1999, 44, 950-972. [CrossRef]

23. Merz, R. Self-generated versus environmentally produced feeding currents: A comparison for the sabellid polychaete Eudistylia vancouveri. Biol. Bull. 1984, 167, 200. [CrossRef]

24. Buss, L.W.; Jackson, J.B.C. Planktonic food availability and suspension-feeder abundance: Evidence of in situ depletion. J. Exp. Mar. Biol. Ecol. 1981, 49, 151-161. [CrossRef]

25. Rodriguez, S.; Patricio Ojeda, F.; Inestrosa, N. Settlement of benthic marine invertebrates. Mar. Ecol. Prog. Ser. 1993, 97, 193-207. [CrossRef]

26. Norkko, A.; Hewitt, J.E.; Thrush, S.F.; Funnell, G.A. Conditional outcomes of facilitation by a habitat-modifying subtidal bivalve. Ecology 2006, 87, 226-234. [CrossRef]

27. Lohrer, A.M.; Rodil, I.F.; Townsend, M.; Chiaroni, L.D.; Hewitt, J.E.; Thrush, S.F. Biogenic habitat transitions influence facilitation in a marine soft-sediment ecosystem. Ecology 2013, 94, 136-145. [CrossRef]

28. Carey, J.; Watson, J. Benthos of the muddy bottom habitat of the Geelong Arm of Port Phillip Bay, Victoria, Australia. Vic. Nat. 1992, 109, 196-202.

29. Preston, F.W. The canonical distribution of commonness and rarity: Part I. Ecology 1962, 43, $185-215$. [CrossRef]

30. Arrhenius, O. Species and Area. J. Ecol. 1921, 9, 95-99. [CrossRef]

31. Carlton, J.T. Biological invasions and cryptogenic species. Ecology 1996, 77, 1653-1655. [CrossRef]

32. Seaward, K.; Acosta, H.; Inglis, G.; Wood, B.; Riding, T.; Wilkens, S.; Gould, B. The Marine Biosecurity Porthole-A web-based information system on non-indigenous marine species in New Zealand. Manag. Biol. Invasions 2015, 6, 177-184. [CrossRef]

33. Ross, D.; Keough, M.; Longmore, A.; Knott, N. Impacts of two introduced suspension feeders in Port Phillip Bay, Australia. Mar. Ecol. Prog. Ser. 2007, 340, 41-53. [CrossRef]

34. Greenfield, B.L.; Kraan, C.; Pilditch, C.A.; Thrush, S.F. Mapping functional groups can provide insight into ecosystem functioning and potential resilience of intertidal sandflats. Mar. Ecol. Prog. Ser. 2016, 548, 1-10. [CrossRef]

35. Thrush, S.F.; Hewitt, J.E.; Kraan, C.; Lohrer, A.M.; Pilditch, C.A.; Douglas, E. Changes in the location of biodiversity-ecosystem function hot spots across the seafloor landscape with increasing sediment nutrient loading. Proc. R. Soc. B Biol. Sci. 2017, 284, 1852. [CrossRef]

36. Chevene, F.; Doléadec, S.; Chessel, D. A fuzzy coding approach for the analysis of long-term ecological data. Freshw. Biol. 1994, 31, 295-309. [CrossRef]

37. Clarke, K.R.; Gorley, R.N. PRIMER v7: User Manual/Tutorial; PRIMER-E: Plymouth, UK, 2015; p. 296.

38. Ellis, J.; Cummings, V.; Hewitt, J.; Thrush, S.; Norkko, A. Determining effects of suspended sediment on condition of a suspension feeding bivalve (Atrina zelandica): Results of a survey, a laboratory experiment and a field transplant experiment. J. Exp. Mar. Biol. Ecol. 2002, 267, 147-174. [CrossRef]

39. Kay, A.M.; Keough, M.J. Occupation of patches in the epifaunal communities on pier pilings and the bivalve Pinna bicolor at Edithburgh, South Australia. Oecologia 1981, 48, 123-130. [CrossRef]

40. Kuhlmann, M. Spatial and temporal patterns in the dynamics and use of pen shells (Atrina rigida) as shelters in St. Joseph Bay, Florida. Bull. Mar. Sci. 1998, 62, 157-179.

41. Zhang, Y.; Silliman, B. A facilitation cascade enhances local biodiversity in seagrass beds. Diversity 2019, 11, 30. [CrossRef]

42. Cummings, V.J.; Thrush, S.F.; Hewitt, J.E.; Turner, S.J. The influence of the pinnid bivalve Atrina zelandica (Gray) on benthic macroinvertebrate communities in soft-sediment habitats. J. Exp. Mar. Biol. Ecol. 1998, 228, 227-240. [CrossRef]

43. Cummings, V.J.; Thrush, S.F.; Hewitt, J.E.; Funnell, G.A. Variable effect of a large suspension-feeding bivalve on infauna: Experimenting in a complex system. Mar. Ecol. Prog. Ser. 2001, 209, 159-175. [CrossRef]

44. Norkko, A.; Hewitt, J.E.; Thrush, S.F.; Funnell, G.A. Benthic-pelagic coupling and suspension-feeding bivalves: Linking site-specific sediment flux and biodeposition to benthic community structure. Limnol. Oceanogr. 2001, 46, 2067-2072. [CrossRef]

45. O’Brien, A.L.; Ross, D.J.; Keough, M.J. Effects of Sabella spallanzanii physical structure on soft sediment macrofaunal assemblages. Mar. Freshw. Res. 2006, 57, 363-371. [CrossRef] 
46. Atalah, J.; Floerl, O.; Pochon, X.; Townsend, M.; Tait, L.; Lohrer, A.M. The introduced fanworm, Sabella spallanzanii, alters soft sediment macrofauna and bacterial communities. Front. Ecol. Evol. 2019, 7, 481. [CrossRef]

47. Beck, M.W. Separating the elements of habitat structure: Independent effects of habitat complexity and structural components on rocky intertidal gastropods. J. Exp. Mar. Biol. Ecol. 2000, 249, 29-49. [CrossRef]

48. Martin-Smith, K.M. Abundance of mobile epifauna: The role of habitat complexity and predation by fishes. J. Exp. Mar. Biol. Ecol. 1993, 174, 243-260. [CrossRef]

49. Chemello, R.; Milazzo, M. Effect of algal architecture on associated fauna: Some evidence from phytal molluscs. Mar. Biol. 2002, 140, 981-990. [CrossRef]

50. Russ, G.R. Effects of predation by fishes, competition, and structural complexity of the substratum on the establishment of a marine epifaunal community. J. Exp. Mar. Biol. Ecol. 1980, 42, 55-69. [CrossRef]

51. Parry, G.; Lockett, M.; Crookes, D.; Coleman, N.; Sinclair, M. Mapping and Distribution of Sabella spallanzanii in Port Phillip Bay; Final Report to Fisheries Research and Development Corporation (FRDC Project 94/164); Victorian Fisheries Research Institute: Queenscliff, Australia, 1996; p. 51.

52. Giangrande, A.; Cavallo, A.; Licciano, M.; Mola, E.; Pierri, C.; Trianni, L. Utilization of the filter feeder polychaete Sabella. Aquac. Int. 2005, 13, 129-136. [CrossRef]

53. Jackson, J.B.C. Competition on marine hard substrata: The adaptive significance of solitary and colonial strategies. Am. Nat. 1977, 111, 743-767. [CrossRef]

54. Schwindt, E.; Bortolus, A.; Iribarne, O.O. Invasion of a reef-builder polychaete: Direct and indirect impacts on the native benthic community structure. Biol. Invasions 2001, 3, 137-149. [CrossRef]

55. Tait, L.W.; Lohrer, A.M.; Townsend, M.; Atalah, J.; Floerl, O.; Inglis, G.J. Invasive ecosystem engineers threaten benthic nitrogen cycling by altering native infaunal and biofouling communities. Sci. Rep. 2020, 10, 1581. [CrossRef] [PubMed]

56. Ross, D.J.; Longmore, A.R.; Keough, M.J. Spatially variable effects of a marine pest on ecosystem function. Oecologia 2013, 172, 525-538. [CrossRef] [PubMed]

57. Jones, C.G.; Lawton, J.H.; Shachak, M. Organisms as ecosystem engineers. Oikos 1994, 69, 373-386. [CrossRef]

(C) 2020 by the authors. Licensee MDPI, Basel, Switzerland. This article is an open access article distributed under the terms and conditions of the Creative Commons Attribution (CC BY) license (http://creativecommons.org/licenses/by/4.0/). 